\title{
Using Service-Learning As A Higher Education Teaching Strategy For Health And Physical Education As Well As The Athletic Setting - A Step By Step Approach
}

Aaron A. Settle, West Virginia State University, USA

Cindi J. Smith, Logan County School System, West Virginia, USA

\begin{abstract}
In recent years, college health and physical educators have examined multiple teaching strategies that enhance students' ability to learn state-required and nationally-required health and physical education standards and outcomes. Identifying such methods and implementing them into courses can be overwhelming and confusing to the college educator. Service learning is a teaching method that best fits into the experimental section of educational foundations. This is an educational method of teaching, learning, and reflection that easily merges traditional classroom curriculum with meaningful community service. This paper provides detailed discussion regarding the service-learning teaching strategy as well as step by step instructions for correct course implementation and optimal educational results.
\end{abstract}

Keywords: service-learning, cognitive, psychomotor, affective, reflection.

\section{INTRODUCTION}

$\mathrm{n}$ recent years, college health and physical educators have examined multiple teaching strategies that enhance students' ability to learn state-required and nationally-required health and physical education standards and outcomes. Accomplishing cognitive, psychomotor and affective outcomes becomes
increasingly critical during the matriculation of health education or physical education-teacher candidate curriculum. Teacher candidates within these areas tend to increase focus on the affective domains of health and physical education due to the fact that college level students, preparing to educate in the health and/or physical education field begin to take on more personal responsibility for, and understanding of, the need for physical activity, health education, health promotion and its role in the fight against disease, developing healthy communities, and living a life of productive work and healthy living. Service learning is a teaching method that best fits into the experimental section of educational foundations. This is an educational method of teaching, learning, and reflection that easily merges traditional classroom curriculum with meaningful community service.

Service-learning is a rapidly growing teaching/learning method that allows health and/or physical education-teacher candidates to learn, refine, and master specific cognitive, psychomotor and affective outcomes. Service-learning not only allows students to learn in class, it also gives the university an opportunity to enhance its visibility and contribution to the surrounding community. This method of teaching allows for extensive practice of a given skill or skill set, civic engagement at a crucial developmentally appropriate time, introduction and mastery of reflective practice and self-assessment, and an overall appreciation for health and physical education outside of the university setting.

Service-learning should not be confused with other academic links to service such as community service or volunteerism (Eyler, J., JGiles, D.). As they complement and support one another, service-learning blends both 
learning and service in a way that both occur at the same time. In addition, service-learning provides a meaningful and requested service to the surrounding community that directly links to learning outcomes associated with the students' teacher education courses. Furthermore, affective appreciation of health and physical education, civic responsibility, and psychomotor mastery of skill must be assessed by other methods besides participation. Assessment strategies used consist of pre and post reflection, evaluation rubrics, and practical application examinations conducted after the service-learning assignment is complete (Campus Compact). Most importantly, a service-learning project that is used for learning psychomotor and affective outcomes must consist of multiple engagements between the students and the organization that is receiving the service. Generally, community service and/or volunteerism only require one or two hours of service with no specific link to an outcome of the course. Service-learning, however, requires a longer commitment from the student to the agency so that appreciation, relationships, civic engagement, and multiple opportunities for learning are more likely to occur.

It is widely known that implementing service-learning into a college level course of any subject is time consuming. It must be reiterated that there are several advantages for teachers who take this challenge and implement this strategy. Using service-learning will allow the health and/or physical education curriculum to be delivered in a richer context. At the college level, service-learning allows students to begin gaining responsibility for what they are learning and allows the teacher to better serve as a mentor or as a "guide on the side." Lastly, in addition to the community and school partnership that is developed, performance-based assessments can be used by the teacher to ensure quality practice and ultimate achievement of psychomotor outcomes.

In addition to the benefits for the teacher and student, a service-learning project in health or physical education can also benefit the university itself. Service-learning can address key educational reform objectives associated with teaching strategies such as cooperative learning and thematic teaching. Also, other faculty and administration involvement as well as public support may increase as they see students' citizenship and community contributions.

There are several avenues by which college health and physical education teachers can begin to incorporate service-learning into their classes. Service-learning could be used as a method for extra-credit, university-wide service theme, independent studies, or most commonly, as an instructional strategy in an existing class. An athletic coach in the college setting could also implement service-learning as a teaching method. As college level athletes work with younger athletes in the community, they can be assessed and evaluated by their coaches in regard to improvements of their skill brought forth by the consistent practice and preparation. Such work provides the community with quality sport and fitness education, while the athletic program and school are gaining public relationships and community support.

To use this strategy to enhance learning of affective and psychomotor outcomes in Health and/or physical education, or to improve athletic skill for university sport programs, a teacher and/or coach should follow these steps: 1) brainstorm, 2) streamline, 3) implement, 4) assess, and 5) reflect (Eyler, J., Giles. D,.).

\section{Step 1: BRAINSTORM}

1. Start with a smaller class or an "advanced" health or physical education class.

2. Identify outcomes that you believe could best be met through service-learning.

3. Contact local organizations that may want your students to visit and teach health content or physical education and fitness skills to individuals. Survey the community for needs and wishes while using local organizations to establish initial contact, such as the American Red Cross, Goodwill, elderly facilities, community centers, elementary schools, and after-school programs.

\section{Example For University Professor:}

You realize, after brainstorming, that your advanced exercise physiology class must further their understanding of the importance of cardiovascular exercise for a healthy life. Furthermore, you gather from previous feedback that the students are unclear on the overload and progression application of the F.I.T principle towards cardiovascular 
exercise. You believe that greater practice and a teaching opportunity that require research, reading, and further practice would be wonderful to optimally achieve this outcome. You contact a local community center or child care center that conducts an after-school program.

\section{Example For Athletic Coach:}

You are an athletic coach at a local university. After pre-season practice you observe that your student-athletes are not passing the ball with the optimal form needed to ensure proper and secure passes. You believe that greater practice and a teaching opportunity that requires research, reading, and further practice would be wonderful to optimally achieve this skill. You contact a local church league basketball team that is looking for any help with coaching their youth as the current youth coaches are volunteer parents who realistically have little knowledge about basketball and the progression of psychomotor skill associated with such basketball skills.

\section{Step 2: STREAMLINE}

1. Make sure that the student and those being served will both benefit equally.

2. Examine issues such as equipment availability, time, and transportation.

3. Provide preservice-learning explanations and rational to your students who will be participating in the project. This will give them a clearer understanding of what they are doing and what is expected of them from both you (the teacher) and the organization they will be serving. Included in your "training," prior to the service-learning project, may be specific issues related to the organization you choose, such as communication with children in an elementary school or after school programs, or possible physical limitations of elderly individuals in other settings.

\section{Example For University Professor:}

Because this is an advanced college course, it was noted that there would be outside assignments associated with the course. You have contacted the child care facility and arranged for your students to assist with their "physical activity time" Monday-Friday from 4:00 p.m -5:00 p.m. Because of transportation issues and possible athletic or other commitments that fall during the specified time frame, you must carefully schedule what day(s) students will be traveling to the child care center. Your class can be represented five days a week at the child care center with only certain students participating on given days. This flexibility usually is sufficient in addressing transportation issues, forming car pools, and adjusting to athletic or university work study requirements. Furthermore, this consistent visualization throughout the week is usually welcomed by the organization you are serving. You may even consider stretching the 10 hour requirement for each student over an extended time period of 6 to 10 weeks.

Hold a training session, which can be class time, with your students explaining in detail what service-learning is and what will be expected of them. In addition, you should explain to the students what will be expected by the child care center. You may want to take class time to perform the pre-reflection for the project and have students share their reflections with one another. During your explanation and discussions, emphasize the fact that the students will be learning, practicing, and mastering skills and knowledge associated with the physical education course at their school.

\section{Example For Athletic Coach:}

You have contacted the local youth church league coaches and gained access to their practice schedule. You adjust your schedule so that your team can travel to the church one night per week to work with the youth team for one hour. You arrange travel with university athletic transportation who regularly schedules athletic transportation. Prior to your first arrival, you assess the equipment availability at the church by a conversation with the coaches. If you need equipment, you can transport the needed items. You may want to take practice time to perform the prereflection for the project and have players share their reflections/thoughts with one another. During your explanation and discussions, emphasize the fact that the athletes will be learning, practicing, and mastering skills and knowledge associated with the skills needed to be successful with their athletic team at the university. 
Lastly, you would want to hold a training session with your athletes explaining in detail what service-learning is and what will be expected of them. In addition, you should explain to the athletes what will be expected by church league players and coaches.

\section{Step 3: IMPLEMENT}

4. Arrange a schedule with the organization that allows your class to visit a minimum of 10 hours.

5. Assign specific tasks that are linked to the psychomotor, cognitive and affective outcomes of the course or specific athletic skills that allow the student or athlete a chance to practice skills and ultimately teach and evaluate others in a setting outside of the university. According to the learning pyramid, students retain 90 percent of what they teach.

\section{Example For University Professor:}

Finalize the schedule with the day care center that best fits transportation and student availability. As the teacher, it would now be appropriate to assign specific content and/or skills that will be taught/practiced while at the day care center. Give the students quality time to research, practice, and learn the topics that they will be teaching to the students at the day care.

\section{Example For Athletic Coach:}

Finalize the schedule with the church and the church league coaches that best fits transportation needs, youth coach availability and church equipment and facility availability. As the coach, it would now be appropriate to assign specific skills that will be taught/practiced while at the church youth basketball practice sessions. Give the players quality time to practice and learn proper cues that can assist in teaching the topics to the youth basketball players.

\section{Step 4: ASSESS}

1. Create an assessment tool to evaluate the students' learning and mastery of psychomotor skill as well as the cognitive, affective and civic growth accomplished during and after the service-learning experience.

2. Create an assessment tool to evaluate the service provided to the organization and its participants. Feedback can serve as vital information to you to improve your service-learning contributions to the community and the entire experience for your students.

\section{Example For University Professor:}

It is important that you develop assessments that will assess the improvement of content knowledge and/or skill for the course, civic responsibility and service appreciation for the student, and quality of service provided to the organization. Generally these are three different assessments. For the example given, the teacher could assess gain in content understanding by assigning each student the role of developing a detailed, multi-week training program utilizing the F.I.T principle. To measure civic responsibility and understanding, a rubric evaluating a pre and post reflection could be used. Lastly, a questionnaire could be developed for the organization/agency to answer upon completion of the service-learning project. These three areas must be assessed to gain an overall assessment of the complete service-learning project. The data can be used to improve the project in future semesters.

\section{Example For Athletic Coach:}

It is important that you develop assessments that will assess the improvement of the psychomotor skills that needed improvement, civic responsibility and service appreciation for the athlete, and quality of service provided to the organization. Generally these are three different assessments. For the example given, the athletic coach could simple use observation of practice and/or competitive game situations in which the skill is used. To measure civic responsibility and understanding, a pre and post reflection that could be video based or individualized testimonials 
to teammates could be used. Lastly, a questionnaire could be developed for the organization/agency to answer upon completion of the service-learning project.

\section{Step 5: REFLECTION}

1. This gives the student an opportunity to examine what they have actually learned from the experience.

2. Gives the students time to examine how their attitudes and thoughts have changed from the experience.

3. Allow reflections to not only be written, but welcome assessments of an alternative nature such as video, Powerpoint presentation, class skit, music, etc.

\section{Example For University Professor And Athletic Coach:}

It is important to realize that reflection can also be and is recommended to be a method of assessment. The reflective piece is used to measure and understand the complete worth of the project on the student or athlete. Typically, the reflection that is used to measure the civic engagement portion of the service-learning project will demonstrate the total worth the project had to the student. Allow multiple methods of reflection to be used such as a pre-reflective paper and post-reflective video, or a pre-reflective video and a post reflective presentation. Allow the student to choose their method of reflection. You may want to direct the reflective piece with a mandatory title such as "Citizenship to me is?" or give specific questions to address in each reflective piece such as, "I felt needed during my experience because?" or "I learned mostly by____ during my project" or "Before the service-learning project I felt ___ about the project, after completion of the project I now feel___ because?

Giving a series of questions or a mandatory theme or title prior to the reflection gives the students and/or athletes a guideline to follow and sparks direction in regards to writing or expression through testimonials, videos, presentations, etc.

\section{CONCLUSION}

Following these guidelines and these recommendations you will be able to implement and utilize a quality service-learning project into your university health and/or physical education class or athletic program. It should be noted that your first attempt should be simple and that implementation across your complete curriculum or season must be of a gradual nature. If this strategy seems a bit overwhelming, consider partnering with another teacher, coach, or an administrator for the experience. As you begin utilizing service-learning as a teaching strategy you will begin to gain confidence in the strategy, strengthen community relationships, enhance student/athlete learning and knowledge/skill retention, and increase school visibility and purpose.

\section{REFERENCES}

1. Eyler, J., \& Giles, D. (1999). Where's the Learning in Service-Learning? Jossey-Bass.

2. Campus Compact,. (2003). Introduction to Service-Learning Toolkit, Reading and Resources for Faculty. 
NOTES 